\title{
Unmet health needs identified by Haitian women as priorities for attention: a qualitative study
}

\author{
Rachel Peragallo Urrutia ${ }^{a}$, Delson Merisier ${ }^{b}$, Maria Small $^{c}$, Eugene Urrutia ${ }^{d}$, Nicole Tinfo ${ }^{e}$, \\ and David K Walmer \\ ${ }^{a}$ Clinical Instructor, Department of Obstetrics and Gynecology, University of North Carolina \\ (UNC), Chapel Hill NC, USA \\ ${ }^{b}$ Adjunct Assistant Professor, Department of Obstetrics and Gynecology, Duke University, \\ Durham NC, USA; and Director of Cervical Cancer Prevention, Family Health Ministries, Chapel \\ Hill NC, USA \\ ${ }^{\mathrm{C}}$ Assistant Professor of Maternal and Fetal Medicine, Department of Obstetrics and Gynecology, \\ Duke University, Durham NC, USA \\ dPhD Student, Department of Biostatistics, UNC Gillings School of Public Health, Chapel Hill NC, \\ USA \\ eDirector of Research, Family Health Ministries, Chapel Hill NC, USA \\ ${ }^{f}$ Associate Professor, Department of Obstetrics and Gynecology, and Associate Professor, Duke \\ Global Health Institute, Duke University, Durham NC, USA
}

\section{Abstract}

This 2009 qualitative study investigated Haitian women's most pressing health needs, barriers to meeting those needs and proposed solutions, and how they thought the community and outside organizations should be involved in addressing their needs. The impetus for the study was to get community input into the development of a Family Health Centre in Leogane, Haiti. Individual interviews and focus group discussions were conducted with 52 adult women in six communities surrounding Leogane. The most pressing health needs named by the women were accessible, available and affordable health care, potable water, enough food to eat, improved economy, employment, sanitation and education, including health education. Institutional corruption, lack of infrastructure and social organization, the cost of health care, distance from services and lack of transport as barriers to care were also important themes. The involvement of foreign organizations and local community groups, including grassroots women's groups who would work in the best interests of other women, were identified as the most effective solutions. Organizations seeking to improve women's health care in Haiti should develop services and interventions that prioritize community partnership and leadership, foster partnerships with government, and focus on public health needs.

\section{Keywords}

accountability; reproductive health policy and programmes; community-based programmes and interventions; donor funding and assistance; Haiti 
Haiti is the poorest country in the Western hemisphere. More than half its residents live on less than one US dollar per day, and accessible health care is not available for the majority of the population. ${ }^{1,2}$ There are only 25 physicians per 100,000 Haitians, and many serve only the upper class. Skilled birth attendants are present for just $26 \%$ of all deliveries. Indicators of reproductive health in Haiti are among the worst in the world. Infant and maternal mortality rates are 64 per 1,000 live births and 630 per 100,000 live births, respectively. ${ }^{3,4}$ Fifty-two percent of Haitian women have an unmet need for contraception. ${ }^{5}$

Poor health in Haiti cannot be understood outside the context of the country's long history of political turmoil. Haiti became a prosperous but brutal French slave colony in 1697 after its indigenous population was decimated during Spanish occupation. In 1791, Haitian slaves won their independence in a bloody revolution. Since then, Haitians have weathered destructive Western interventions and occupations, internal governmental instability, and frequent episodes of violence. The brunt of these effects is felt by the large numbers living in poverty, who continue to be oppressed, under-educated and denied the fruits of millions of dollars of financial aid and donations, pocketed by their leaders. ${ }^{6-9}$ The mountainous terrain, ecological devastation, poor roads, natural disasters, and reliance on traditional healers present additional challenges to providing health care.

Leogane is a port town two hours drive from Port au Prince, Haiti's capital, surrounded by mountainous rural communities and the site of frequent flooding. Much of the population sought health care at the local multidisciplinary charity hospital, ${ }^{10}$ but that hospital closed its inpatient services in January 2008. After this study, Leogane was the epicentre of the January 2010 earthquake, and indigent patients had to travel hours to Port-au-Prince, Petit Goave or Jacmel to receive hospital care, though outpatient services overseen by the Haitian Ministry of Health did continue to be provided. Additional health resources in Leogane include an expensive private hospital, several private clinics with varying levels of international support, a public maternity hospital in neighbouring Carrefour, a women's health clinic through Family Health Ministries, a Filariasis research project, and a Children's Nutritional Program. ${ }^{10}$ In the rural areas, several small clinics provide first aid and children's nutrition, overseen by nurses and public health workers (Telesmanick K, Children's Nutrition Program. Personal communication, 2009). Additional community resources include the university in Fondwa, a microloan agency in Leogane and Fondwa, and a peasant's foundation in Fondwa.

Women in Leogane have long expressed a desire for a women and children's health centre. Family Health Ministries, a US non-profit organization, is supporting this community initiative. Their vision is to focus on local priorities and complement existing health services. They carried out a community survey of existing health services in Leogane in 2007. ${ }^{10}$ However, more information was needed. Our goal was to gain this information from local women, using qualitative methods. Women from Leogane were asked to identify their most pressing health needs, barriers to meeting those needs, and how they thought the community and outside organizations should be involved in addressing those needs.

\section{Methodology}

A literature review was performed in PubMed, Web of Science, and Google Scholar using MeSH terms "Haiti" and "women's health" or "pregnancy" or "maternal mortality", "Haiti" and "corruption", "Haiti" and "focus groups". Key references were identified and their bibliographies searched for additional relevant publications. Multiple barriers to health care (financial, geographic and limited resources), reliance on alternative health practitioners (traditional birth attendants, herb doctors, spiritual practitioners), and attribution of disease to spiritual causes were identified as important issues. A brief individual interview script 
was prepared to collect demographic information, current access to care and important health needs.

A focus group discussion (FGD) script was developed to explore themes identified in the literature review and questions deemed important by those planning the Women's Health Centre and Haitian field workers. The script encouraged women to list and prioritize their five most important health needs, explored barriers to care arising from the literature review, and asked them to propose health care solutions. The questions and informed consent documents were translated and back translated from English to Kreyol by local field staff.

We planned to recruit 6-12 women to each group from among women likely to seek health care in Leogane. Saturation of qualitative themes is usually reached after at least two FGDs with each group of interest. ${ }^{11}$ Six groups were planned: three in Leogane town and three in surrounding rural communities. Researchers modified the interview guide for later groups in order to incorporate knowledge gained from earlier sessions.

The inclusion criteria were: female, Haitian, 18 years and older to capture women's experiences across all age groups, mother of at least one child, and Kreyol speaking. A local Voudou leader, who directed an educational non-profit, recruited the first urban group; the other two were recruited among women awaiting cervical cancer screening at a Family Health Ministries cervical cancer screening clinic. These two groups included women from Carrefour (7 out of 13) and Port au Prince (3 out of 13) who were seeking health care in Leogane. A nurse from a public health outpost ${ }^{*}$ funded by the Children's Nutritional Program recruited one rural group in Troinn, located one hour by bus, 30 minutes by motorcycle taxi or half a day's walk from Leogane. A second rural group was from a Fondwa local peasant's association women's group, 90 minutes by bus and a one-mile mountain walk from Leogane. The third was from a Children's Nutritional Program safe water education session, located in Darbonne, 30 minutes by bus from Leogane.

Bilingual research assistants from the community were employed and trained to conduct the individual interviews and focus group discussions using published curricula. ${ }^{12}$ Individual interviews were conducted privately before the FGDs; the latter lasted 40-90 minutes and were audio-recorded.

Descriptive statistics for the demographic information (Table 1) were calculated using the SAS means, median and freq procedures (SAS Institute Inc). Responses regarding health needs were grouped in similar categories, and total numbers of responses in each category were calculated using the SAS freq procedure.

The interviews were read as they were transcribed, and common themes were noted. All transcriptions were read a second time while listening to the audio recording to verify accuracy. The data were analyzed on an ongoing, iterative basis to develop a summary of common themes. ${ }^{13}$ A list of themes for health needs, barriers to care and solutions was created after review of the transcripts. Final codes were decided upon by agreement between one author and two independent reviewers. Responses were aggregated using NVivo (QSR International) to create summary matrices. Health needs of women and their families, barriers in gaining access to health care, and proposed health care solutions were the primary focus.

\footnotetext{
* She had not received her salary in 18 months.
} 


\section{Findings}

\section{Participant characteristics}

Responses from 52 women were included in the analysis. One participant did not complete the individual interview but completed the focus group discussion. Another completed the individual interview but only part of the focus group discussion. The remaining 50 participants completed both. FGDs ranged in size from 6 to 13 women. All but one lasted 60-90 minutes; one was 40 minutes and was interrupted several times.

Demographic information is shown in Table 1 . The mean age of participants was 39 . The average household size (5.9) was slightly larger than the national average (4.6). The average number of pregnancies and living children was similar to the 2011 estimated total fertility rate in Haiti of 3.07. Marital status was also similar to national averages. Education levels were low; the majority of women had not completed primary education, consistent with national data (4\% of Haitians complete high school and only $2 \%$ have any education beyond secondary school). ${ }^{14}$

\section{Health needs}

The five most important health needs named by the women individually are shown in Table 2. Nutritious food and drink were the most commonly mentioned (24\%), and at least 15 of 38 mentions of food were directly related to not having enough to eat (more common among urban women). Other important needs were access to affordable and available medical care (17\%), potable water (16\%), education/training, enough work/improved economy, hygiene/ bathing and improved sanitation (all 5-7\%). Although "happiness" and "belief in God" may not reflect direct health needs, they represented $5 \%$ of the responses.

The FGDs echoed these (Table 2), mentioning hunger/malnutrition, contaminated water and poor access to hospitals as of primary importance.

"We have not eaten anything since this morning... some parents do not have anything to give their children. They leave for school in the morning and come back home without eating anything."(Leogane 1, urban)

"Clean water is a big problem... Soon it will be rainy season and this means that in the coming days, children and the elderly will suffer from diarthoea... We have to wait for the river to go back down to dig a hole in the riverbed to find some water. Sometimes you drink the water even when... it can have more microbes in it." (Troinn, rural)

"We can't find a hospital close by... If I were a chief the first thing I would do is build... a big hospital in order to have many doctors always available. Not just doctors who come and go, but [are there] whenever, day or night."(Fondwa, rural)

The majority of the discussion in all focus groups was on barriers to health care. Groups rarely discussed specific diseases and when they did, they linked them to larger public health issues. Four groups mentioned family planning and the need for more education for themselves and younger women about how to prevent pregnancy.

"Sometimes people have many [health] problems and they would leave their houses but because there is no money to go to the hospital or they cannot get to where the hospital is, they stay, waiting, waiting. When the pain is worse, they will take the patient out [to the hospital], but before they arrive in Port au Prince, the patient dies on the road." (Darbonne, rural) 


\section{Household income and health care}

The median monthly income was US $\$ 100$ per month (data not shown), consistent with yearly per capita GDP of US\$1200 in 2010. ${ }^{15}$ Eleven households had no income; eight women did not know their household income. Lack of income, unemployment and cost of health care presented financial barriers to health care. Forty-one percent of Haitians are currently unemployed. ${ }^{15}$

"We are living in a community where you can't find jobs, where you can't find anything to do... There is nothing to do in order to make a living or to be healthy." (Fondwa, rural)

During the focus group discussions, women reported the following costs for health care: US $\$ 125-\$ 400$ for caesarean section or other hospitalization during pregnancy, US\$25 for a home birth with a lay midwife, US\$1.25-\$20 for prescriptions, US\$6 to consult a general physician, US $\$ 25$ to consult a specialist, and $\$ 10-50$ for various tests. Vaccinations, subsidized by the government, were least costly: less than $\$ 1$ each. Every FGD reported similar costs, and when compared to median household income, the financial barrier was obvious. In general, costs were lower in public and private charity hospitals and higher in private hospitals. Giving birth or seeing a doctor at a public hospital could cost as little as US\$6. However, these hospitals have other problems such as long queues.

"That is why, when you go to the public hospital, you will see a crowd there because there is not money in the country to see private doctors."(Lcogane 2 , urban)

"I have children. When they are sick, I can find money for the [doctor] appointment, but after that, I don't have money to do the tests or buy the medicines."(Darbonne, rural)

"Sometimes pregnant women would like to go to the hospital but because they don't have money, they don't go... They stay home counting on God.”(Darbonne, rural)

Having witnessed a complication in other women, such as obstructed labour, haemorrhage or pre-eclampsia, many women wanted to deliver their babies at the hospital. However, the majority reported using a traditional birth attendant or none at all due to cost.

\section{Distance from services and lack of transport}

There were significant barriers in accessing health care due to the distance to clinics and hospitals. Women reported a mean of 84 minutes travel time to the nearest health care facility. Several women had to travel $2-3$ hours just to get to a rural health outpost. A private hospital, Petit Goave, was mentioned, a one-hour drive from Leogane and expensive. A maternity clinic in Carrefour that provided subsidized care was 30 minutes drive from Leogane.
"A lot of women die giving birth because they live so far away... they die on the way because there is no road and because transportation is not easy! to find." (Troinn, rural)
"If you are going to give birth and your feet and clothes are dirty, they will not even look at you. They will tell you to go away and walk in the yard. And then, you will push out your baby there in the yard."(Troinn, rural)

Cost of transport, lack of suitable vehicles, and inadequate roads were discussed in all but one urban group. Transport costs for non-emergency appointments were less than a dollar, but paying for a car to the hospital in an emergency was US $\$ 10$ in Leogane and US\$40 from 
Fondwa. In urban areas, tap-taps (local buses) are much more affordable than private cars, but they are crowded, slow and do not go to two of the communities in this study. Women from those communities had to pay for a private car or walk, sometimes in labour, to the nearest tap-tap stop. Motorcycle taxis go to rural areas but cannot be counted on with any regularity, and not everyone is able to travel on the back of a motorcycle, e.g. women in labour.

"When someone has contractions and she does not have a friend to drive her to the hospital, sometimes she gives birth to the baby wherever she happens to be. And after that, she could call a matwon (midwife) to cut the cord or she could walk waddling until she finds a motorcycle taxi, a tap-tap, or a car to rent"(Leogane 2, urban)

For emergencies, women in five groups, including two urban ones, mentioned the makeshift stretcher or chair, which sometimes required paying the bearers.

"... they could put them on a stretcher, carry the person on their heads... or, they could sit the person on a chair and use two pieces of wood and then they could carry the person on their shoulders."(Darbonne, rural)

\section{Accessible and available medical care}

When asked where they currently sought medical care, 29 women said they went to private physicians or clinics, 12 to hospitals in Jacmel or Port au Prince located two hours drive from Leogane, and 10 to the hospital in Leogane which had not offered inpatient services for over a year. Private hospitals were more accessible for many women, but they were more expensive. The only government-funded inpatient hospitals mentioned were in Port au Prince and Jacmel. Yet several women from the capital had travelled to Leogane to have a Pap smear, and for many, it was their first smear test.

The lack of available and affordable hospitals was a major barrier to obtaining health care discussed by five out of six FGDs. The only group that did not mention this barrier was composed mostly of women from Carrefour, closer to Port au Prince, where the public maternity hospital was located. In any case, there were not always enough or appropriate medical staff to see patients. Traditional birth attendants were frequently used for deliveries; in fact, women made no mention of trained midwives.

"One of my friends had a problem that needed a caesarean. They sent her to Petit Goave. When she arrived there, they asked her for US\$125 to do her delivery, but she only had US\$37 in her purse and she was obliged to return to Port au Prince, so that means if she were going to die, she would have died travelling." (Leogane 2, urban)

"They sent me to see a gynaecologist but what happened is that every day I went and never found a doctor to take care of me. Then I became angry and gave up." (Leogane 3, urban)

"I know there is a hospital where you don't need to pay a lot of money. You pay [less than US\$0.20]. There are some good paediatricians there... but you spend all day there and you never see the doctor."(Darbonne, urban)

On the other hand, all the groups spoke highly of some Haitian medical providers who they admired: several local physicians who cared for poor women, a nurse who ran a first aid and nutrition clinic in the mountains, and the public health nurse:

"The nurse [at the public health outpost] does not now receive a salary. She risks her life every Monday through Thursday to come here, but in some cases she can't 
keep taking care of us because she does not have all the right equipment in the clinic. Sometimes she uses her own money to buy medicines but she does not receive any money. The people respect her because she cares for them with her own sweat." (Troinn, rural)

\section{Corruption, lack of infrastructure and social organization}

Corruption in the government and among medical professionals, lack of infrastructure and security, ineffective government health efforts and inadequate public health information contributing to poor health were strong themes in all groups. Participants believed Haitians with power usually would not help poor women. Some women I reported paying bribes at public hospitals to be seen in time.

"We not only lack institutions to take care of the people but also we lack education. If the people were at least educated, they would know that when they are sick, they would have to go see a doctor."(Leogane 2, urban)

Women in two groups mentioned the need for more education about how to take care of common health problems. Women in one of these groups had been attending a course on water safety that same day and desired more health information.

\section{Traditional and spiritual beliefs and practices}

Spiritual beliefs and practices were not barriers to seeking medical care. Each FGD had a strong consensus that if resources were available to them, they would seek Western medical care first for illnesses.

"What I think can help people when they are sick, first of all, is money, and after that, you need doctors. After that, it's prayer that can help you."(Fondwa, rural)

Some women from each group said they would eventually consult a Voodoo priest (houngan) or clergy for spiritual care during an illness, especially if Western medicine did not yield the desired outcome quickly. However, there were exceptions.

"The fever got into the head of that one and he became delirious. He ripped his clothes off and they did not give him any medicine. They took a stick and they beat him. They beat him saying he had a demon on him until he died."(Darbonne, rural)

Women in all groups differentiated between "doctor illnesses" and "houngan illnesses". The latter were described as being caused by a "fetish" or "demon", and patients might be taken to a spiritual healer (houngan or pastor) before a doctor. Another category of illnesses, "hot" and "cold" illnesses, led some people to see a herb doctor who would make poultices and teas for the patient. These illnesses cannot be described in Western medical terms.

"I had a son who was sick. I went to see a doctor with him... and he did not really have a doctor sickness. The doctor told me, 'If you hospitalize him, he will die.' So I went to see an houngan with him because the child's soul was not on his body, and the priest put his soul back on him."(Troinn, rural)

"When you catch a chill, sometimes you get an attack of cold joints. Sometimes you get angry and your milk goes into your body and that can lead you to a herb doctor."(Leogane 1, urban)

\section{Solutions to health needs}

All groups more or less agreed on what was needed, but when asked how the changes they wanted could be effected, their responses differed. One group had no idea and seemed quite hopeless about change. The other five groups spoke highly of foreign organizations and 
partnerships, and believed they would be more likely to offer health care solutions and financial transparency than Haitian government initiatives.

"We are living off foreign aid... Most of the time, you can find a foreigner to take care of you but a Haitian would not For many things that we would like to solve, if there were at least one foreigner involved, it would be solved."(Leogane 2, urban)

"When it is a Haitian [distributing foreign aid], he might just use the money to get a visa and leave the country without doing anything."(Leogane 2, urban)

One urban and one rural focus group believed that grassroots women's organizations offered an equally important opportunity for improved health, and that women's groups could be trusted to work in the best interests of other women. The remaining focus groups thought community organization would be helpful but prioritized foreign assistance.

"If there was a women's organization, we could together analyze and say what we would like to do. We could put our heads together and see how we would like the zone to be involved." (Darbonne, rural)

"To aid the people, the women should get together so they can help themselves. Then they won't be dependent on other people... I think women can help most. It is women who put each other first... They see other women who are suffering... In Haiti, women do not have any value at all."(Leogane 1, urban)

Ideas for women's group activities included educating youth about health, educating more women, political advocacy for community needs, collaborating with foreign organizations, manual labour at hospitals and clinics, motivating other women in the community to make healthy choices, and developing small business or selling/commerce through micro-loans. One rural group described how they assisted in building a local health clinic.

"We climbed the mountain day and night to carry water. It was difficult and we did it for free. We did not receive anything for it, but now, we come here to the centre and they give us some health care and we don't give a lot of money for it We see our work was not in vain." (Fondwa, rural)

"We women should meet with the government, heads of state, so they can help us and then they will be able to help the other women because we don't have means by ourselves." (Leogane 1, urban)

Since the completion of data collection for this study, a women's group in Leogane has been formed. They meet regularly and advise on the development of the health centre. Their numbers have grown (to over 100), and they are advocating together for community needs. Needs addressed include safe motherhood, stress management and family planning. Some are receiving training to be community health advocates. Many will be given jobs in the centre.

\section{Discussion}

A strength of our data was the demographic similarity between participants in our convenience sample and the Haitian population in census level data. In addition, common themes were agreed upon by women from Port au Prince, rural mountain areas, and the town of Leogane. This implies an adequate sample of women. A possible limitation was that interview questions were not validated prior to their use. For example, we asked: "How much money passes through your home each month?" Responses may not have taken into account the bartering and exchange of labour that often occurs in Haiti without use of money. Moreover, our study was sponsored by a Christian faith-based organization, and the

Reprod Health Matters. Author manuscript; available in PMC 2013 July 01. 
women may have expressed a preference for Western medical care and been less forthcoming about their spiritual practices as a result.

We found that the most pressing health needs of Haitian women were access to health care, clean water, enough food, improved economy, sanitation, and education. Differences between rural and urban populations were not unexpected. Overall, the women were less concerned about specific diseases than about basic public health issues. International organizations that provide health care in Haiti should consider these priorities. For example, WHO goals such as supply of essential medicines and equipment, potable water, and operating rooms were shared by the women, ${ }^{3}$ but no mention is made of the problems of poverty and malnutrition, which are pervasive. ${ }^{2}$ Improving the economic situation of Haitian women would reduce negative health outcomes such as forced sex, sexually transmitted diseases and unwanted pregnancy. ${ }^{16,17}$

The multiple, systemic, financial and logistical barriers to health care experienced by the women have not changed in 20 years, and were exacerbated by the earthquake. ${ }^{6,18-21}$ The Haitian government and international organizations must find creative ways to remove these barriers. Corruption is recognized by the Haitian government and the World Bank as "a manifestation of multi-faceted, systemic weaknesses that can only be addressed through a broad program of governance, public sector reform and broader accountability throughout Haitian society and government." 22

The women's most frequently suggested solution to corruption was to circumvent Haitian organizations by involving foreign organizations, and foreign organizations frequently urge this too. However, although Haitians received an estimated US\$4 billion in foreign aid between 1990 and 2003, they saw little direct benefit. ${ }^{6,23}$ Foreign provision of health care, though trusted by the women, may interfere with the development of more sustainable, effective, culturally relevant projects in the longer term. The trust in foreign organizations could be engaged to support community leadership of fiscally transparent health care projects and partnerships with the Haitian government.

Haiti is known for its spiritual culture and has an active network of spiritual healers and lay health providers like traditional birth attendants and herbalists. Coreil et al found that mental illnesses may be more likely than other diagnoses to be called "houngan illnesses". ${ }^{24}$

Spiritual beliefs and reliance on traditional healers did not seem to be a large barrier to care among Haitian women. ${ }^{25}$ Reliance on traditional birth attendants, though, seemed to be due to the lack of accessible, available skilled attendants.

\section{Conclusions and recommendations}

Based on our findings, we recommend that any organization seeking to provide health care in Haiti should begin with community partnerships, in order to understand the communitylevel effects of funding and interventions. ${ }^{17}$ Emergency hospitals and funds alone are not enough. Ideally, this approach should be "bottom-up" with needs, barriers, and solutions elicited from the community. Qualitative methods have been used successfully in Haiti and elsewhere to develop community-based health interventions addressing maternal mortality, HIV transmission, vaccine uptake, tuberculosis treatment and nutrition programmes. ${ }^{26-29}$ Western care providers should have open communication about spiritual and traditional beliefs with Haitian patients. Finally, the provision of health care services should be as multi-faceted as possible. Haitian women wanted improvements in economics, sanitation and education more than they wanted treatment for specific conditions. It would be impossible for any one organization to meet all of these needs, but partnerships between organizations could provide additional services and support. 
In Leogane, the Family Health Centre was planned in direct response to community needs, and our research findings have led to a more formal partnership between the Centre and the community, informing decision-making about organization, services and priorities. The focus group discussions led to the development of a new women's group, which acts as an advisory panel and actively participates in programme planning and community education. For example, after the earthquake, the women requested assistance in dealing with stress disorders; over 50 have now participated in training to recognize and provide support for stress disorders in the community.

Partnerships between communities and nonprofit organizations should include key local leaders and stakeholders who are trusted by the community. The majority of the board of the Leogane Family Health Centre are Haitian, and include a local pastor, a local lawyer, several local physicians, a local nursing instructor and several community members. The Centre has a long-standing relationship with local spiritual leaders, and the Centre campus will include a chapel for spiritual meetings and a community centre. Ongoing communication with the community is planned, to better understand the spiritual implications of health care for them. A partnership has also been created with local traditional birth attendants, who are receiving training and resources relating to safe birthing practices and emergency transportation of patients with obstetric complications. The Centre has also developed partnerships with the Haitian Ministry of Health, Haitian Obstetrics and Gynaecology Society, a cancer nonprofit started and led by Haitian women, and a Haitian non-profit focused on HIV prevention. This has led to the development of national cervical cancer screening recommendations and the opportunity to offer both HIV and cervical cancer screening to Haitian women around the country.

Family Health Ministries' work with a local Peasant's Foundation has led to financial support for a local elementary school. Children receive financial support to attend school and are given a nutritious meal and periodic screening and treatment for parasites and malaria. Promising graduates are assisted as they enter high school. Some have been sent to nursing school or hired by FHM. A community education facility is planned as part of the Family Health Centre. The vast majority of Centre employees will be local, providing income for their families. A system of emergency transportation is being planned to connect the Health Centre with the surrounding rural communities and TBAs.

Once a community-centred partnership has been created, attempts should be made to involve Haitian governmental and non-governmental organizations, with the aim of improving longterm sustainability. Zanmi Lasante (Partners in Health), a US non-profit, has used this model in Haiti. ${ }^{30}$ By involving community health workers in directly observed treatment protocols, they have been very successful at treating HIV-related illness and multi-drug resistant tuberculosis in a Haitian community, and are currently collaborating with the Haitian government to open a national teaching hospital staffed by Haitians.

The Haitian Health Foundation, a community-centered non-profit with 23 years experience in rural Haiti, includes traditional healers, traditional birth attendants and Voudou priests in their community outreach. ${ }^{31}$ Both Zanmi Lasante and the Haitian Health Foundation include education and economic empowerment as part of their mission and practice (Judy Lewis, Haitian Health Foundation, Personal communication, January 2012). A local micro-loan organization Fonkoze is also available in Leogane.

With the involvement of Haitian women, we have developed a framework for understanding and addressing their most pressing health needs in Haiti. Our community survey model could easily be modified for use in other low-resource settings and could be especially 
useful when foreign organizations desire to learn how best to meet the expressed needs of a community with the resources available.

\section{Acknowledgments}

The authors wish to thank Mr Oscar Wilkens for translation and Dr Michelle Graziano for assisting with data analysis.

\section{References}

1. Sletten, P.; Egset, W. [Accessed 7 February 2011] Poverty in Haiti; Fafo. 2004. p. 31At: http:// www.ht.undp.org/_assets/fichier/publication/pubdoc28.pdf

2. Doctors without Borders. [Accessed 7 February 2011] MSF in Haiti. Dec. 2008 At: http:// doctorswithoutborders.org/news/country.cfm?id=2323

3. World Health Organization. [Accessed 7 February 2011] Health Action in Crisis, Haiti. Nov. 2004 At: http://www.who.int/hac/crises/hti/background/2004/Haiti_Nov04.pdf

4. UNICEF. [Accessed 6 February 2012] At a glance: Haiti: Statistics. 2009. At: http:// www.unicef.org/infobycountry/haiti_statistics.html\#80

5. Sedgh, GRH.; Bankole, A.; Singh, S. Occasional Report. New York: Guttmacher Institute; 2007. Women with unmet meed for contraception in developing countries and their reasons for not using a method.

6. Farmer, P. The Uses of Haiti. 2. Monroe, ME: Common Courage Press; 2006.

7. Klitgaard, R. Addressing corruption in Haiti. Claremont Graduate University; 2010. At: http:// www.cgu.edu/pages/6259.asp [Accessed 19 July 2011]

8. King-Schultz L, Jones-Webb R. Multi-method approach to evaluate inequities in prenatal care access in Haiti. Journal of Health Care for the Poor and Underserved. 2008; 19:248-57. [PubMed: 18264000]

9. Gibbons E, Garfield R. The impact of economic sanctions on health and human rights in Haiti 1991-1994. American Journal of Public Health. 1999; 10:1499-504. [PubMed: 10511830]

10. Liu, M. Evaluation of Healthcare for Women and Children in Leogane, Haiti. Durham, NC: Duke University; 2007.

11. Guest G, Bunce A, Johnson L. How many interviews are enough? An experiment with data saturation and variability Field Methods. 2006; 18:59-82.

12. Mack, N.; Woodsong, C.; MacQueen, KM., et al. Qualitative Research Methods: A Data Collector's Field Guide. Chapel Hill NC: Family Health International; 2005.

13. LeCompte, M.; Schensul, J. Analyzing and Interpreting Ethnographic Data. Vol. 5. Thousand Oaks CA: AltaMira Press (Sage); 1999.

14. Cayemittes, M.; Placide, MF.; Mariko, S., et al. Enquête mortalité morbidité et utilization des services, Haiti, 2005-2006. Calverton, MD: Ministére de la Santé Publique et de la Population, Institut Haïtien de I'Enfance et Macro International; Jan. 2007 At: http://www.measuredhs.com/ pubs/pdf/FR192/FR192.pdf [Accessed 12 March 2012]

15. Central Intelligence Agency. [Accessed 28 January 2012] World Factbook: Haiti. At: https:// www.cia.gov/library/publications/the-world-factbook/geos/ha.html

16. Fawzi MCS, Lambert W, Singler JM, et al. Factors associated with forced sex among women accessing health services in rural Haiti: implications for the prevention of HIV infection and other sexually transmitted diseases. Social Science \& Medicine. 2005; 60:679-89. [PubMed: 15571887]

17. Maternowska, MC. Rutgers Studies in Medical Anthropology. New Brunswick, NJ: Rutgers University Press; 2006. Reproducing inequities: poverty and the politics of population in Haiti.

18. Anderson FW, Naik SI, Frees SA, et al. Perceptions of pregnancy complications in Haiti. International Journal of Gynecology and Obstetrics. 2008; 100:116-23. [PubMed: 18076885]

19. White K, Small M, Frederic R, et al. Health seeking behaviour among pregnant women in rural Haiti. Health Care for Women International. 2006; 27:822-38. [PubMed: 17060181]

20. Barnes-Josiah D, Myntti C, Augustin A. The Three Delays as a framework for examining maternal mortality in Haiti. Social Science \& Medicine. 1998; 46(8):981-93. [PubMed: 9579750] 
21. Thaddeus S, Maine D. Too far to walk: maternal mortality in context. Social Science \& Medicine. 1994; 38:1091-110. [PubMed: 8042057]

22. World Bank. Haiti Governance Diagnostics. Washington DC: World Bank; May. 2007 (undated), Final Report (in French)At: http://web.worldbank.org/WBSITE/EXTERNAL/WBI/ EXTWBIGOVANTCOR/0,,contentMDK:20750460 pagePK:64168445 piPK:64168309theSitePK: 1740530,00.html [Accessed 7 February 2011]

23. Buss, T.; Gardner, A. Summary Report. Washington, DC: National Academy of Public Administration; Feb. 2006 Why foreign aid to Haiti failed. International Affairs SeriesAt: www.napawash.org/wp-content/uploads/2006/06-04.pdf [Accessed 7 February 2011]

24. Coreil J, Lauzardo M, Heurtelou M. Cultural feasibility assessment of tuberculosis prevention among persons of Haitian origin in South Florida. Journal of International Health. 2004; 6(2):6369.

25. Desrosiers A, St Fleurose S. Treating Haitian patients: key cultural aspects. American Journal of Psychotherapy. 2002; 36(4):308-21.

26. Loechl CU, Menon P, Arimond M, et al. Using program theory to assess the feasibility of delivering micronutrient Sprinkles through a food-assisted maternal and child health and nutrition program in rural Haiti. Maternal and Child Nutrition. 2009; 5(1):33-48. [PubMed: 19161543]

27. Rosato M, Mwansambo CW, Kazembe PN, et al. Women's groups' perceptions of maternal health issues in rural Malawi. Lancet. 2006; 368:1180-88. [PubMed: 17011945]

28. Kershaw TS, Small M, Joseph G, et al. The influence of power on HIV risk among pregnant women in rural Haiti. AIDs and Behavior. 2006; 10:309-18. [PubMed: 16482404]

29. Coreil J, Augustin A, Holt E, et al. Use of ethnographic research for instrument development in a case-control study of immunization use in Haiti. International Journal of Epidemiology. 1989; 18(4 Suppl):S33-S37. [PubMed: 2621046]

30. Sloand E, Astone NM, Gebrian B. The impact of fathers' clubs on child health in rural Haiti. American Journal of Public Health. 2010; 100(2):201-04. [PubMed: 20019318]

31. Farmer P, Leandre F, Mukherjee JS, et al. Community-based approaches to HIV treatment in resource-poor settings. Lancet. 2001; 358:404-09. [PubMed: 11502340] 


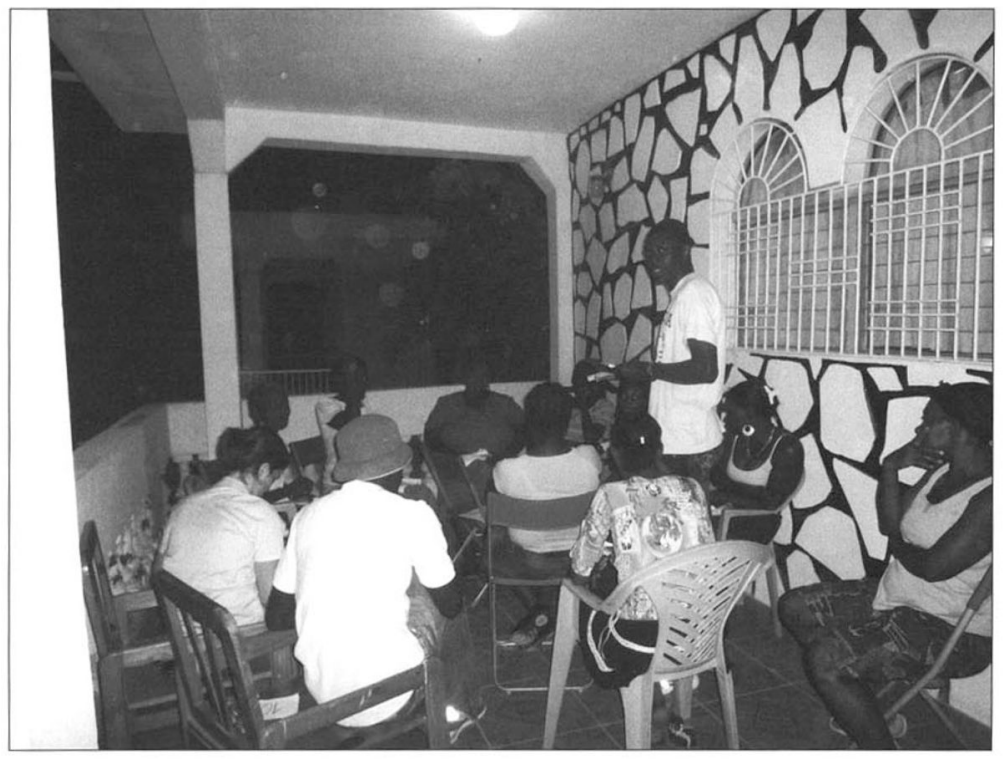

1.

First author Rachel Peragallo leading a focus group discussion, Leogane, Haiti 
Table 1

Demographic characteristics of participants $(n=52)$

\begin{tabular}{|lc|}
\hline & Mean or Per cent (Range) \\
\hline Age (years) & 39.1 years (22-58) \\
\hline Household size & 5.9 people (1-20) \\
\hline Education years in school & $7.0(0-19)$ \\
\hline Median monthly income & US\$IOO (\$0-\$1525) \\
\hline Pregnancies & $3.6(0-11)$ \\
\hline Live births & $3.2(0-11)$ \\
\hline Live children & $3.0(0-9)$ \\
\hline Children in school & $2.6(0-8)$ \\
\hline Time to reach hospital & 84 minutes (5-240) \\
\hline Married & $33.3 \%$ \\
\hline Single & $21.6 \%$ \\
\hline Living together & $35.3 \%$ \\
\hline Widowed & $9.8 \%$ \\
\hline Children vaccinated & $100 \%$ \\
\hline
\end{tabular}


Table 2

Priority health needs named during individual interviews and focus group discussions: frequency of mention

\begin{tabular}{|lcc|}
\hline Health needs & Frequency: individual interviews (n=52) & Frequency: focus group discussions (n=6) \\
\hline Food/nutrition & 38 & 6 \\
\hline Accessible health care & 31 & 6 \\
\hline Potable water & 30 & 6 \\
\hline Schools/education & 12 & 2 urban, 3 rural \\
\hline Personal hygiene & 12 & 1 urban, 1 rural \\
\hline Jobs/improved economy & 11 & 2 urban, 3 rural \\
\hline Improved sanitation & 10 & 2 urban, 3 rural \\
\hline Happiness/security/peace & 6 & 3 urban \\
\hline Healthy drinks/juices & 6 & 1 urban \\
\hline Roads & 5 & 1 urban, 3 rural \\
\hline Vaccines & 4 & 2 rural \\
\hline Exercise & 4 & urban \\
\hline Good sleep & 3 & none \\
\hline Belief in God & 3 & 2 urban, 1 rural \\
\hline Insects/malaria prevention & 2 & 2 rural \\
\hline Medicines & 2 & 2 rural \\
\hline Social services & 1 & none \\
\hline Vaginal infections & 1 & 3 urban, 1 rural \\
\hline HIV testing & 1 & rural \\
\hline Family planning & 1 & urban, rural \\
\hline Improved housing & 1 & none \\
\hline Orphanages & 1 & \\
\hline
\end{tabular}

